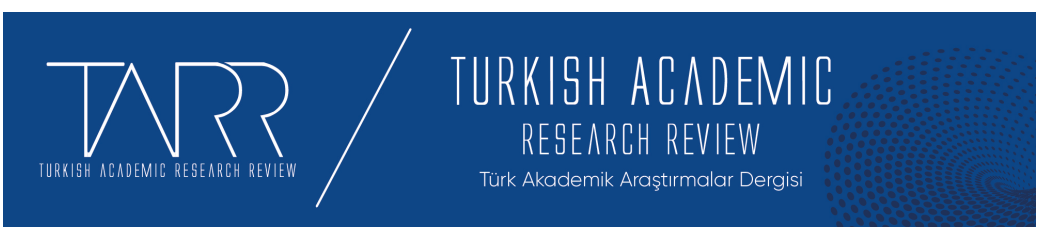

e-ISSN: 2602-2923 Yıl/Year: 2021 Cilt/Volume: 6 Sayı/Issue: 5

\title{
Kaynak Mobilizasyon Kuramı Çerçevesinde Yehova Şahitlerinin Üye Kazanma Yöntemlerinin Tespiti ve Değerlendirilmesi (Antalya Örneği)
}

Detection and Evaluation of Recruitment Methods of Jehovah's Witnesses in The Framework of Resource Mobilization Threory (Example of Antalya)

\section{Salih Emre KARAYEL - Ali ALBAYRAK}

Doç. Dr., Akdeniz Üniversitesi İlahiyat Fakültesi, Din Sosyolojisi Anabilim Dalı/Assoc. Prof., Akdeniz University, Faculty of Divinity, Department of Sociology of Religion, alialbayrak@akdeniz.edu.tr, Orcid ID: https://orcid.org/00000003-0558-2612

Doktora, Akdeniz Üniversitesi, Sosyal Bilimler Enstitüsü, Felsefe ve Din Biimleri, emrehey@hotmail.com, Orcid ID: 0000-0002-0272-135X

\begin{tabular}{r|l} 
Makale Bilgisi & Article Information \\
Makale Türü - Article Type & Araştırma Makalesi / Research Article \\
Geliş Tarihi - Date Received & 12 Kasım / November 2021 \\
Kabul Tarihi - Date Accepted & 28 Aralık / December 2021 \\
Yayın Tarihi - Date Published & 31 Aralık / December 2021 \\
Yayın Sezonu & Aralık Özel Sayı \\
Pub Date Season & December Special Issue
\end{tabular}

Atıf / Cite as: Karayel, S.E.- Albayrak, A., (2021), Kaynak Mobilizasyon Kuramı Çerçevesinde Yehova Şahitlerinin Üye Kazanma Yöntemlerinin Tespiti Ve Değerlendirilmesi (Antalya Örneği)/Detection and Evaluation of Recruitment Methods of Jehovah's Witnesses in The Framework of Resource Mobilization Threory ( Example of Antalya). Turkish Academic Research Review, 6 (5), 12721292. Retrieved from https://dergipark.org.tr/tr/pub/tarr/issue/67845/1022514

Intihal / Plagiarism: Bu makale, en az iki hakem tarafından incelenmiş ve intihal içermediği teyit edilmiştir. / This article has been reviewed by at least two referees and confirmed to include no plagiarism. https://dergipark.org.tr/tr/pub/tarr

Copyright (C) Published by Mehmet ŞAHIN Since 2016- Akdeniz University, Faculty of Theology, Antalya, 07058 Turkey. All rights reserved.

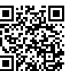

Turkish Academic Research Review - Türk Akademik Araştırmalar Dergisi 


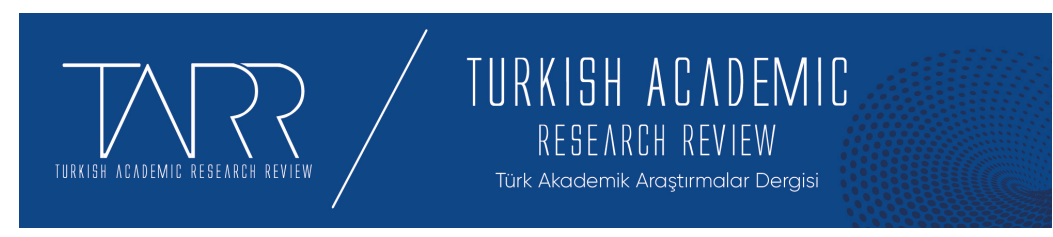

e-ISSN: 2602-2923 Yll/Year: 2021 Cilt/Volume: 6 Sayı/Issue: 5

\title{
Kaynak Mobilizasyon Kuramı Çerçevesinde Yehova Şahitlerinin Üye Kazanma Yöntemlerinin Tespiti ve Değerlendirilmesi (Antalya Örneği)
}

\author{
Salih Emre KARAYEL - Ali ALBAYRAK
}

\section{$\ddot{\mathbf{O} z}$}

Yeni dini hareket (YDH)'ler kavramı, genellikle 1950'li yıllardan itibaren farklı inanç, ibadet, yaşam tarzı ve ideolojileriyle ortaya çıkan dini grupları ifade etmek için kullanılmaktadır. Özellikle dinin toplum hayatındaki işlevinin sona erdiğinin düşünüldüğü bir devirde çeşitli sebep ve amaçlarla ortaya çıkan bu oluşumlar, sosyal ve dini yaşamda var olan etkisini sadece içinden çıktığı toplumlarda değil, dünyanın pek çok ülkesinde de hissettirmeyi başarmıştır. Post-modern dünyada modern ve modern öncesi dönemin kutsallarını da bünyesinde barındıran Yeni Din Hareketlerin seküler dünyanın beğeni ve kaygılarını da göz önünde tutarak bireylerin manevi hazlarını tatmin etme amacı güttüğü görülmektedir. Son yıllarda başta sosyolog ve teologların dikkatini çekmeyi başaran yeni dini hareketler birçok araştırmacının üzerinde çalıştığı konular arasında yer almaktadır.

$\mathrm{Bu}$ oluşumlardan birisi olan Yehova Şahitleri 19. yüzyılın sonlarına doğru Amerika Birleşik Devletleri'nde Mesih İsa'nın yeniden dünyaya geleceğini iddia eden Adventizm akımı içinden çıkan dini bir gruptur. Yehova Şahitlerinin gerek teşkilat yapısında gerekse inanç sistemindeki temel özelliklerin Hristiyanlığın yerleşik öğretilerinden farklılık arz ettiği görülmektedir. Bu sebeple araștırmacılar Yehova Şahitlerini yeni dini hareketler kategorisi içerisinde değerlendirmiştir. Hiyerarşik bir yapıya sahip olan ve en nihayetinde kesin emirleri Yönetim Kurulu'ndan alan Şahitler buradan gelen emirleri Tanrı'nın emri olarak algılamakta ve Dünya'nın her yerinde bu emirleri uygulamaya çalışarak buna göre faaliyetlerini yürütmektedirler. Yehova Şahitleri yeryüzünde Tanrı'nın hâkim olacağı bir teokratik devlet modelini savunduğu için hiçbir devletin otoritesini tanımamaktadır. Teşkilat, üyelerinden mensubu oldukları milletlerin kurucu değerlerine ve kişilerine göstereceği en küçük olumlu hissiyatı putperestlik ve isyan olarak görmektedir. Tüm dünyada çeşitli yönleriyle tartışılan bu yeni ve alternatif oluşumun ülkemizde de faaliyetleri bulunduğu bilinmektedir.

Yehova Şahitlerinin ülkemizde en yoğun faaliyette bulunduğu illerden birisi de Antalya'dır. Yehova Şahitlerinin bu bölgede yoğun faaliyette bulunmalarının başlıca sebebi Antalya ilinin turizm merkezi olması ve yabancı uyruklu kişilerin de bu bölgeyi tercih etmesidir. Ayrıca yakın geçmiş zamanda faaliyetleri sebebiyle hakkında açılan davalarda beraat kararının verilmiş olması teşkilata daha rahat etme hareket imkânı sağlamıştır.

Anahtar Kelimeler: Yeni Dini Hareketler, Yehova Şahitleri, Kaynak Mobilizasyon, Misyonerlik, Kutsal Kitap

Turkish Academic Research Review - Türk Akademik Araştırmalar Dergisi 


\title{
Detection and Evaluation of Recruitment Methods of Jehovah's Witnesses in The Framework of Resource Mobilization Threory (Example of Antalya)
}

\begin{abstract}
The concept of new religious movements (NRM) is generally used to express religious groups that have emerged with different beliefs, worship, lifestyles and ideologies since the 1950s. These formations, which emerged for various reasons and purposes, especially in a period when it was thought that the function of religion in social life was over, He succeeded in making his influence felt in social and religious life not only in the societies he came from, but also in many countries of the world. In the post-modern world, it is seen that the New Religious Movements, which also contain the sanctities of the modern and pre-modern era, aim to satisfy the spiritual pleasures of individuals by taking into account the tastes and concerns of the secular world. In recent years, new religious movements, which have managed to attract the attention of sociologists and theologians, are among the subjects that many researchers are working on.

One of these formations, Jehovah's Witnesses is a religious group that emerged from the Adventist movement in the United States towards the end of the 19th century, claiming that Jesus Christ would be reborn. It is seen that the basic features of Jehovah's Witnesses both in their organizational structure and in their belief system differ from the established teachings of Christianity For this reason, researchers have evaluated Jehovah's Witnesses in the category of new religious movements. Witnesses, who have a hierarchical structure and ultimately receive strict orders from the Governing Body, perceive the orders coming from it as God's orders and try to implement these orders all over the world and carry out their activities accordingly. Jehovah's Witnesses do not recognize the authority of any state, as they advocate a model of a theocratic state in which God will rule the earth. The Organization considers the slightest positive feeling its members show towards the founding values and persons of the nations they belong to as idolatry and rebellion. It is known that these new and alternative formations, which are discussed in various aspects all over the world, also have activities in our country.

One of the cities where Jehovah's Witnesses are active in our country is Antalya. The main reason why Jehovah's Witnesses are active in this region is that Antalya is a tourism center and foreign nationals also prefer this region. In addition, his acquittal from the lawsuits brought against him due to his activities in the recent past has provided the organization with a more comfortable movement.
\end{abstract}

Keywords: New Religious Movements, Jehovah's Witnesses, Resource Mobilization, Missionary, Bible

Turkish Academic Research Review - Türk Akademik Araştırmalar Dergisi 


\section{Structured Abstract}

The concept of new religious movements is generally used to express religious groups that have emerged with different beliefs, worship, lifestyles and ideologies since the 1950s. These formations, which emerged for various reasons and purposes, especially in a period when it was thought that the function of religion in social life was over, he succeeded in making his influence felt in social and religious life not only in the societies he came from, but also in many countries of the world. In the post-modern world, it is seen that the New Religious Movements, which also contain the sanctities of the modern and pre-modern era, aim to satisfy the spiritual pleasures of individuals by taking into account the tastes and concerns of the secular world. In recent years, new religious movements, which have managed to attract the attention of sociologists and theologians, are among the subjects that many researchers are working on.

One of these formations, Jehovah's Witnesses, is a religious group that emerged from the Adventist movement in the United States towards the end of the 19th century, claiming that Jesus Christ would be reborn. It is seen that the basic features of Jehovah's Witnesses both in their organizational structure and in their belief system differ from the established teachings of Christianity. For this reason, researchers have evaluated Jehovah's Witnesses in the category of new religious movements. Witnesses, who have a hierarchical structure and ultimately receive strict orders from the Governing Body, perceive the orders coming from it as God's orders and try to implement these orders all over the world and carry out their activities accordingly. Jehovah's Witnesses do not recognize the authority of any state, as they advocate a model of a theocratic state in which God will rule the earth. The Organization considers the slightest positive feeling its members show towards the founding values and persons of the nations they belong to as idolatry and rebellion. It is known that these new and alternative formations, which are discussed in various aspects all over the world, also have activities in our country.

One of the cities where Jehovah's Witnesses are active in our country is Antalya. The main reason why Jehovah's Witnesses are active in this region is that Antalya is a tourism center and foreign nationals also prefer this region. In addition, his acquittal from the lawsuits brought against him due to his activities in the recent past has provided the organization with a more comfortable movement.

It is a fact that in today's world where globalization and digitalization are dominant, every new thought and ideology is met with doubt and hesitation. Likewise, the New Religious Movements, which started to become more visible on the stage of history especially after the $1950 \mathrm{~s}$, faced similar problems as other social movements. It is seen that these movements, which are aware of this, have developed some methods and strategies in order to eliminate negative thoughts and hesitations about themselves, to connect people to them, and to recruit members.

It is not an easy process for people to become members of these new formations. Even when committed to new religious Movements, it is not easy for new members to act in line with the group's goals. In some cases, the emergence of the movement's inability to realize its goals has led to separations and ruptures within the group. Sometimes these formations may encounter serious resistance and even open opposition from other segments of society. Long-term and effective work is required for the realization of the change desired by the movement. In this process, new members should be replaced and resources should be renewed in order to ensure stability. The desire of the New Religious Movements to become widespread by finding a social base has attracted the attention of social scientists, and they have developed some theories and models in order to better explain the tendency towards these movements and formations. Especially 19. The process of participation in the social and religious movements that emerged during the rapid 
change and transformation process in the 19th century was mostly explained with psychological motifs; however, with the introduction of sociological researches, new approaches have been put forward on how and in what way these formations are formed. One of these models is "resource mobilization theory". It is seen that this theory focuses on the ability of groups to have resources and to mobilize them, rather than psychological factors in explaining the formation and development processes of social movements. The subject of this research is to examine the methods of gaining followers within the framework of the resource mobilization theory of Jehovah's Witnesses.

The problem of this research consists of the questions of what methods the Witnesses apply to recruit new members to the group within the framework of Resource mobilization theory, where they use their material and human resources power more, and what kind of strategy they follow in order to mobilize their members in this regard.

In order to answer these questions, on the one hand, the activities of Jehovah's Witnesses in our country were examined, on the other hand, information was given about the activities carried out within the framework of resource mobilization theory, which is a common practice in recruiting new religious movements. The research consists of two stages: theoretical and practical. At the theoretical stage, a literature review about Jehovah's Witnesses was made, and the documentation method was applied as a method. In this direction, information about the activities they have done in Turkey has been reached in the light of the data obtained by scanning the literature on domestic and foreign sources written about Jehovah's Witnesses. The practical phase of the study was limited to the province of Antalya, where the Witnesses are active. The meetings and activities of the Witnesses in Antalya were examined using the participant observation and interview technique, and the data obtained were interpreted.

In this study, it has been determined that Jehovah's witnesses, who have a disciplined and authoritarian organizational structure, effectively use the potential of trained human resources as well as the monetary power emphasized by the resource mobilization theory. It is seen that the Witnesses, who feel obliged to convey the truth to all humanity, carry out an intensive preaching service both in terms of social relations and through the virtual environment. In this context, it is possible to say that human resources are actively used in the field services of the movement, and that they are also effective in the digital environment in terms of spreading their ideas and communicating with their members.

\section{Giriş}

Ülkemizde yıllardır Hristiyanlık ve onun farklı bir uzantısı durumundaki dini oluşumların misyonerlik faaliyetleri bilinen bir gerçektir. $\mathrm{Bu}$ çerçevede en çok adından söz ettiren dini hareketlerden birisi de Yehova Şahitleridir. Bu hareket Türkiye'deki faaliyetlerinde istediği neticeyi uzun yıllar sonra elde edebilmiştir. Nitekim bununla ilgili olarak Russell'in 1891 senesinde Avrupa'yı dolaşmak için çıktığı bir yolculuk sırasında aktarılan bir anektoda göre Anadolu'ya uğradığı ve hayal kırıklığı içinde ayrıldığı kayıtlara geçmiştir (Yasdıman, 2005: 209). Hatta Anadolu'dan ayrılırken şu sözleri söylediği nakledilmektedir: “Türkiye’de bir hasadın olmasını ümit etmek için hiçbir hakikate karşı hiçbir istidat görmüyorum." Onun bu umutsuzluk dolu sözlerine rağmen şahitler, yine de Anadolu'da 
1276 Kaynak Mobilizasyon Kuramı Çerçevesinde Yehova Şahitlerinin Üye Kazanma Yöntemlerinin Tespiti ve Değerlendirilmesi (Antalya Örneği)

teşkilatlanma faaliyetlerine devam etmişlerdir. Nitekim bu oluşumun 1909 yılında İzmir'de The Watch Tower dergisi okuma grubu oluşturdukları bilinmektedir. Yehova Şahitlerin Türkiye'deki asıl teşkilatlanma serüvenin başlangıcını ise 1931 tarihine kadar götürmek mümkündür (Tınaz,2013:395). Bu tarihte Emmanuel Pasavantis (Tümer, 1996: 58) ve eşi Zimini öncülük hizmetinde bulunmak amaciyla İstanbul'a gönderilmişlerdir. Beyoğlu semtinde daire tutan bu çift (Yasdıman,2011:70), daha sonra Hristiyan azınlık grupları ve özellikle Rum Ortodoks cemaati arasında bu hareketin inanç esaslarını anlatmaya ve yayınlarını dağıtmaya başlamışlardır. Bu girişimlerin neticesinde 1933 yılının ilkbaharında gerçekleş̧irilen, Şahitlerin Rabbin Akşam Yemeği dedikleri ve İsa'nın vefatını anma gecesi olarak organize ettikleri ayine 22 kişi katılmış, aynı yıl içinde 5 kişi vaftiz olmuştur. Daha sonra bu küçük grup da propaganda faaliyetlerine dahil olup ev ziyaretleri gerçekleştirmiş ve yayın dağıtımı yapmıştır. 1934'te teşkilatın o zamanki başkanı olan Rutherford'un bu hareketin Türkiye'de meşruiyet kazanması ve var olan üyelerin desteklenmesi için Emmanuel Pasavantis'e mektup yazdığı, mektubunda da Yehova Şahitleri'nin Amerikan hükümeti tarafindan resmen tanındığına dair belgeyi gönderdiği söylenir. Hatta bu mektubun Türkiye'deki makamlara ulaştırılması ile ilk resmi temasın sağlandığından da bahsedilebilir (Tinaz, 2013: 395).

1938 yılında teşkilata sempati duyanların sayısının 100'e ulaşması üzerine teşkilat Gilead Okulu'ndan 17 misyoneri ve belli sayıdaki öncüyü Türkiye'ye yollamıştır. (Yasdıman,2005: 210). 1956 yılında teşkilatın yönetim kurulu üyelerinden olan Knorr ve Franz'ın Türkiye'yi ziyaretleriyle birlikte Türkiye'deki Yehova Şahitliği teşkilatlanma aşamasına geçmiş ve akım sadece azınlık cemaatleri arasında değil Müslümanlar arasında da yayılmaya başlamıştır. Bu dönemde Şahitliği kabul edenlerin başında Türkiye'deki Temsil Heyeti başkanlığını yürüten Mete Süer gelmektedir (Tinaz, 2013: 395).

Şahitlerin, yasaların verdiği haklardan istifade ederek 1961 yılından itibaren, nüfus kayıtlarındaki din hanesinde değişiklik yaptırıp Yehova'nın Şahidi ya da Hıristiyan yazdırmaya başladıkları görülmektedir. Yehova Şahitleri Mukaddes Kitap Kursları Derneği kurmak için 10 Temmuz 1974 tarihinde Beyoğlu Kaymakamlığı'na başvuruda bulunmuşlardır. Başvuruları onaylanmadan ilk toplantılarını 17 Kasım 1974'te İstanbul Osmanbey'de gerçekleştirmişlerdir. 21 Mayıs 1975 'te tüzüğün onaylanmasının ardından dernek, faaliyetlerine yoğunluk vererek İstanbul'un bazı semtlerinde Ankara, İzmir ve Antakya gibi şehirlerde şubeler açıp toplantılar organize etmişlerdir. Grubun Temsil Heyeti 28 Mayıs 
1980'de Mete Süer, Vartan Mumcu ve Yılmaz Ertuncalı'nın önderliğinde Beyoğlu'nda ilk bürosunu açmıştır. (Yasdıman, 2005: 210-211; Tınaz, 2013: 396).

$\mathrm{Bu}$ gelişmelerin ardından Yehova Şahitleri'nin faaliyetleri dava konusu olur. Mahkeme ve tutuklama aşamalarına geçilir. 1940’lardan 1980'lerin sonuna kadar eden süreçte 50'yi aşkın dava açılır. Açılan bu davalar beraatla sonuçlanır ve Şahitler daha rahat hareket etmeye başlarlar (Türkiye'de Yehova Şahitleri, 2001: 45). 1984-1985 yılları ise Şahitler için kolay olmamıştır. Bu yıllarda Ankara ve İzmir'de tutuklamalar meydana gelmiştir. 1986' da verilen beraat kararı artık Şahitler için önemli bir hukuki karardı (Türkiye'de Yehova Şahitleri, 2001: 8). Bundan sonra Şahitler ile ilgili tahkikatlar sonlanır. 1996'da Yehova Şahitleri ile ilgili bir davanın onlar açısından olumlu neticelenmesinden sonra ise artık günümüzde Yehova Şahitleri faaliyetlerini daha rahat sürdürmektedirler. Yehova Şahitleri bugün ellerindeki mahkeme karalarını ülkemizde yayınladıkları yayınlarına koyarak meşruiyetlerini kanıtlamaya çalışmaktadırlar (Yasdıman, 2011: 71-73). Teşkilatın 2019 yılı faaliyet raporlarına göre Şahitler'in Türkiye'deki cemaat sayısı 52, müjdeci sayısı da 4.221 olarak ifade edilmiştir (https://www.jw.org/tr/yehovaninsahitleri/dunya-capinda/TR/).

Yehova Şahitleri'nin Türkiye'de yoğun faaliyet gösterdiği bölgelerin başında Ege bölgesi gelmektedir. Özellikle bu hareket için İzmir'in ayrı bir önemi vardır. Yehova Şahitleri'nin üyelerinin ifadeleri de bu görüşü destekler niteliktedir. Örneğin, bir dönem Türkiye'de görevli olarak bulunan ve şu an organizasyonun merkezinde çalışan Rendall Hickok son zamanlarda Müslüman asıllı Türkler arasında Yehova Şahitliği'nin rağbet gördüğünü söyleyerek İzmir'deki 400 Yehova Şahidi mensubuyla Türkiye'nin önde gelen şehri olduğunu belirtmektedir. Bu ili İstanbul, Ankara, Mersin takip etmektedir (Yasdıman, 2005: 128; Aydın, 2010: 278). Yehova Şahitleri’nin Ege Bölgesi’nden sonra etkin olduğu bir başka bölge ise Marmara'dır. Bu bölgede de başta İstanbul olmak üzere büyük şehirlerde Yehova Şahitleri faaliyetlerini sürdürmektedir. Akdeniz, İç Anadolu, Karadeniz bölgeleri de faaliyetlerin yoğunluğu bakımından bu iki bölgeyi takip eden bölgelerdir (Yasdiman, 2011: 79-80).

$\mathrm{Bu}$ araştırmanın konusu Yehova Şahitleri’nin kaynak mobilizasyon kuramı çerçevesinde taraftar kazanma yöntemleridir. Araştırmanın problemini ise Yehova Şahitleri'nin gruba yeni üye kazandırmak için hangi yöntemlere müracaat ettikleri, maddi ve insan kaynakları gücünü daha çok nerelerde kullandıkları, bu konuda mensuplarını harekete geçirebilmek için nasıl bir strateji takip ettiği soruları oluşturmaktadır. Bu sorular çerçevesinde araştırmada yeni dini hareketlerin üye

Turkish Academic Research Review - Türk Akademik Araştırmalar Dergisi https://dergipark.org.tr/tr/pub/tarr 
1278 Kaynak Mobilizasyon Kuramı Çerçevesinde Yehova Şahitlerinin Üye Kazanma Yöntemlerinin Tespiti ve Değerlendirilmesi (Antalya Örneği)

kazanma noktasında yaygın bir uygulama olan kaynak mobilizasyon kuramına başvurularak Yehova Şahitlerinin ülkemizde yaptıkları faaliyetleri incelenmiştir.

Bu sorulara cevap vermek için bir yandan Yehova Şahitleri’nin ülkemizde yürüttüğü faaliyetler incelenmiş, diğer yandan da Yeni dini hareketlerin üye kazanma noktasında yaygın bir uygulama olan kaynak mobilizasyon kuramı çerçevesinde yürütülen faaliyetler hakkında bilgi verilmiştir. Araştırma teorik ve pratik olmak üzere iki aşamadan oluşmaktadır. Teorik aşamada Yehova Şahitleri ile ilgili literatür taraması yapılmış, metot olarak da dokümantasyon metodu uygulanmıştır. Bu doğrultuda Yehova Şahitleri hakkında yazılmış yerli ve yabancı kaynaklar üzerinden literatür taraması yapılarak elde edilen veriler ışığında Türkiye'de yapmış oldukları faaliyetler ile ilgili bilgilere ulaşılmıştır. Çalışmanın pratik aşaması Şahitlerin yoğun faaliyette bulunduğu Antalya ili ile sinırlı tutulmuştur. Katılımcı gözlem ve mülakat tekniği kullanılarak Şahitlerin Antalya'da yapmış olduğu toplantı ve faaliyetler incelenmiş, elde edilen veriler yorumlanmıştır.

\section{Kaynak Mobilizasyon Kuramı}

Batı dünyasında yeni dini hareketlerin niçin ve nasıl ortaya çıktığıyla ilgili birçok teori ortaya atılmıştır. Bu hareketlere yönelişi anlamak ve açıklamak üzere geliştirilen teorilerden birisi de kaynak mobilizasyon kuramıdır. John McCarthy ve Mayer Zald (1977) tarafından geliştirilen Kaynak Mobilizasyon Kuramı toplumsal hareketleri kar, zarar, maliyet, gider, gelir ve kaynak gibi ekonomik terimlerle açıklamaya çalışan bir yaklaşımı benimser. Bu yaklaşıma göre, bir toplumsal hareketin ortaya çıkması için ihtiyaç duyulan kaynakları harekete geçirmek ve bu kaynakların verimli bir şekilde kullanılmasını sağlamak önem arz etmektedir. Buna göre, bu kaynakların kullanımı sadece bireyin tekelinde olamayacağından, bu kaynakların nasıl kullanılacağı girişimler ve örgütler tarafından da tanımlanabilir (McCarthy \& Zald, 1977: 4-5). Bir sosyal veya toplumsal hareketin ortaya çıkış sürecinde duygusal yönelimler tek başına yeterli değildir. Bunun yanında para, siyasal/sosyal nüfuz, medya/iletişim kanalları bağlantıları ve personel gibi birçok kaynağa da gereksinim duyulmaktadır. Kaynak mobilizasyonu paradigması işte tam bu ihtiyaçlar bağlamında şekillenmektedir. Bu tür kaynaklar olmazsa olmaz bir özellik taşıdığı gibi sosyal hareketlerin başarıya ulaşmasında da etkin rol oynarlar. Kaynakların niceliği ve bu kaynakların etkin ve verimli kullanımı başarı oranını yükselten etkenlerdir (Schaefer, 2013: 483-484). Sosyal hareketlere kaynak sağlama noktasında her şey maddi imkanlarla açıklanamamaktadır. Bazı hareketler, varlıklarını paradan çok gönüllülerin emeğine ve ona ayırdığı zamana borçludurlar. Büyük parasal kaynaklarla desteklenmeyen hareketlerde bu olgu daha net görülebilir (Uysal, 2009: 227). 
Sosyologların yeni dini hareketlerin oluşum ve gelişim aşamalarının açıklanmasında, üye kazanma stratejilerinin analizinde kullandığı yaklaşımlardan birisi de kaynak mobilizasyon kuramıdır (Kirman,2010:228). YDH'ler tıpkı sosyal ilişkilerin güçlü olduğu toplumsal örgütlenmelerde olduğu gibi müntesiplerini ilk önce kendi doktrinleri etrafinda toplar. Ancak hareketin doktrinel boyutunun etkili olabilmesi için birtakım kaynaklarla desteklenmesi gerekir (Stark,2003:263). Özellikle dini grubun büyümeye başlamasıyla lider kadronun üstlendiği zaman, para, insan kaynakları temin etme gibi görevlerin sorumluluğunu üyeler üstlenmeye başlar. Diğer sosyal faaliyetlerde olduğu gibi dini faaliyetlerin de yürütülmesi için kaynakların harekete geçirilmesi gerekmektedir. Burada en önemli kaynak insandır. En büyük sorumluluk görevleri yeni üyeler kazandırmak olan grup üyelerine düşmektedir (Bilgin,2020:312). Yeni dini hareketler sadece ideolojiler yoluyla üye devşirmezler. Ekonomik kaynaklarını da harekete geçirmek zorundadır. Verdikleri hizmetlerin bazıları, belirli aralıklarla toplantılar organize etme, okuma kampları düzenleme, hafta sonu pikniği. kamp gibi toplu şekilde bir yerlere gitmektir. Bu etkinliklerin yanında gelir getirici her türlü meşru ticaret faaliyeti kaynak hareketliliği arasında gösterilebilir (Bird ve Wesltley,1985:163) Yeni Dini hareketler üyelerinden tam bağlllık ve maddi ve manevi enerjilerini grup faaliyetleri için ayırmalarını talep etmektedir. Hatta bundan da öteye giderek hareketin karizmatik liderleri sempatizanlarına aile ve çevresiyle olan ilişkilerini kesmeleri yönünde baskıda da bulunmaktadır (Kirman,2004:64).

Yeni dini hareketler sosyolojisi bağlamında incelendiği zaman Yehova Şahitlerinin üye kazanma yöntemleri kaynak mobilizasyon kuramı ile örtüşmektedir. Bu çerçevede Yehova Şahitleri'nin üye kazanma yöntemlerini şu şekilde açıklamak mümkündür:

\section{Sosyal İlişkilerden Yararlanma}

YDH'lerin faaliyetlerine katılanlar hakkında genel görüşlerden birisi de onların öncesinde tanığı kişiler vasıtasıyla bu hareketlere sempati duydukları ve inançlarını değiştirdiği şeklindedir. İnsanlar YDH'lerin inanç ve ritüellerini etkileyici buldukları için katılmazlar. Ne zaman ki grubun üyeleriyle olan ilişkiler grubun dişındakilerle olan ilişkilere üstün gelirse o zaman değişim gerçekleşir (Stark,2003:267). Ayrıca Dawson'un (2003:134) da vurguladığı gibi harekete üye kazandırma noktasında arkadaş arkadaşı, aile bireyleri birbirlerini, komşusunu yönlendirebilmektedir. Teşkilatın, her kesim ve yaştan insana ulaşmak için müjdecileri yönlendirdiği bilinmektedir. Şahitlerden, bir mahalledeki eve en azından yılda bir kere ziyaret yapılması istenilmektedir. $\mathrm{Bu}$ ev ziyaretlerinde aile fertlerinden birisine ulaşıldığı takdirde ailenin diğer üyelerine de ulaşmak daha kolay olmaktadır.

Turkish Academic Research Review - Türk Akademik Araştırmalar Dergisi 
1280 Kaynak Mobilizasyon Kuramı Çerçevesinde Yehova Şahitlerinin Üye Kazanma Yöntemlerinin Tespiti ve Değerlendirilmesi (Antalya Örneği)

Hatta bir evden istenilen sonuç alınamazsa, yandaki komşuyla irtibata geçilerek sonuç almak için uğraşılmaktadır (Yasdıman,2011:81).

Şahitlerin ev ziyareti yaparken nasıl bir yol izledikleri kendi ifadeleriyle şu şekilde açıklanmaktadır: "Şahitlerin Tanrı'nın Gökteki Krallı̆̆ı'nın iyi haberini duyururken amaçları, asla insanları bir dine girmeleri için zorlamak veya rahatsız etmek değildir. Kapısına Yehova'nın Şahidi gelen kişiler bunu bilir. Kapıyı açınca size güler yüzle anlamlı resimler içeren bir dergi ya da küçük kitap gösteren biriyle karşılaşırsınız. Eğer Mukaddes Kitap hakkında konuşmak istemezseniz ya da onunla ilgili yayınları almak istemezseniz Şahit saygılı bir şekilde oradan ayrılacaktır. Fakat ilgilenir ve sorular sorarsanız, Şahit size seve seve bilgi verecektir. Yehova'nın şahitleri, Tanrı'nın sözünü incelemek isteyen kişilerle konuşmaktan mutluluk duyar” (Türkiye'de Yehova Şahitleri, 2001: 9).

Ev ziyaretlerini gerçekleştiren ekiplerce küçük bir çocuk arabasının içine çocuktan başka, o gün dağıtılacak yayınlar da konulmakta ve genç bir kadın ve erkek üyeden oluşturulması tercih edilmektedir. Bu saf ve masum aile görüntüsü, temiz kıyafetli, iyi görünümlü ekiplerin mülayim tavırlarla kapısı çalınan insanları etkileme amacının güdüldüğü anlaşılmaktadır (Yasdıman, 2011: 87). Üyelerin tebliğ amacıyla aynı mekanlara bıkmadan usanmadan defalarca gittikleri ve davetlerini tekrar ettikleri de bilinmektedir. (Aydın, 2010: 278).

Görüşmemiz sırasında $\mathrm{H}$. Bey’e Yehova şahitlerinin tebliğ faaliyetlerine neden "tarla hizmeti" olarak adlandırdıklarını sorduğumuzda Tanrı Yehova'nın “Hasadın Efendisi” olduğunu Kutsal Kitap’ta İsa’nın kuyu başında mola verdikleri bir yerde öğrencilerine "Başınızı kaldırın ve hasadı bekleyen şu ağarmış tarlalara bakın" (Yuhn. 4:35) dediğini, İsa'nın gerçek bir hasattan söz etmediğini, insanlık dünyasının 'hasadı bekleyen ağarmış tarlalara benzetildiğini ve Şahitlerin iyi haberi tüm insanlığa duyurarak aslında en büyük hasat işinde çalışsığını ifade etti. H. Bey, Şahitlerin Tarla hizmetinde çalışabilmek için yaşam tarzları ve alışkanlıklarında değişiklikler olması gerektiğini kumar, içki, cinsel ahlaksızlık gibi kimsenin bilmediği ciddi günahları bırakmış olması gerektiğini belirtti. Hüseyin Bey’e Şahitlerin Antalya'da belirli günlerde mi tarla hizmetinde bulundukları sorulduğunda bu durumun değişkenlik gösterdiğini, kesin gün veya zaman diliminin bulunmadığını belirtti. İsteyen herkes Yehova Şahidi olabilir mi diye sorduğumda ise bana bir kişinin Yehova Şahidi olabilmesi için bazı şartları yerine getirmesi gerektiğini söyledi. Bu şartlardan birincisi Kutsal Kitab'ın ne öğrettiğini öğrenmek, ikincisi öğrendiği bilgileri hayatın her alanında tatbik etmek, üçüncüsü de vaftiz olmaktır. 
YDH'ler ile ülkemizdeki dini grupların sosyal ilişkilerden faydalanarak üye kazanma yöntemleri arasında benzerlik bulunmaktadır. Bu konuda Bodur'un YDH'lerden biri kabul edilen Moon Tarikatı'yla ilgili yaptığı çalışmasında ortaya koyduğu tespitler dikkat çekicidir. Bodur'a göre eğitim veya başka sebeplerden ötürü yer değiştirmek zorunda kalan, ailesinden uzaklaşan bireyler, yabancılaşma veya yalnızlık tecrübesi yaşama durumunda kalabiliyor. Bu durumdaki bireyler duygusal anlamda desteğe ihtiyaç duyabiliyor. Gençler, anominin neden olduğu gerginlikten kurtulmanın yollarını arıyor. $\mathrm{Bu}$ arayış sürecinde önüne çıkan seçeneklerden birisi de yeni dini gruba bağlanmaktır. Mesela sırt çantasıyla kampüs alanında gezinen ve yalnızlık tecrübesi yaşayan gençler, cemaat evine çağrılarak burasının kendileri için son derece rahat ve güvenli olduğu vurgulanır. $\mathrm{Bu}$ mekânlardaki çeşitli programlar aracılığıyla bir şekilde grupla ilişki kurmaya başlayan potansiyel cemaat adayının gruba kazandırılması için yoğun emek harcanır. $\mathrm{Bu}$ bağlamda çeşitli olaylara dinî veya manevî anlamlar verildiğini anlamaya başlayan üye olmaya aday gençlerin, cemaat evlerindeki diğer üyelerle girdiği yoğun etkileşim neticesinde grubun mesajını kabul etme yönünde bir eğiliminin olmasından söz edilebilir (Bodur, 2003: 27).

Bodur'un bu tespitlerinde gençlerin potansiyel hedef seçilmesi dikkat çekicidir. Şahitler de, özellikle genç kuşağın içine düştüğü bu anomi durumundan istifade etmeye çalışmaktadır. Bilhassa gençlerin yoğun bulunduğu internet cafe gibi mekanlar ve başta İzmir olmak üzere Aydın ve Muğla gibi üniversitesi olan iller tercih edilmektedir (Yasdıman, 2011:78-79).

\section{Yayın Faaliyetleri}

Enformasyon Çağı olarak adlandırılan günümüz dünyasında bilişim ve iletişim teknolojilerinin gelişmesiyle beraber basım ve yayın tekniklerinin çeşitlenmesi her türlü bilgi ve habere hızlı ulaşmayı kolaylaştırmıştır. Dünya'nın herhangi bir noktasında basılan bir kitap kısa süre içinde istenilen bir dile çevrilip dünyanın diğer bir ucuna rahatlıkla ulaştırılabilmektedir. Üstelik bu işlem eskiden olduğu gibi yüksek bir maliyet ve zaman gerektirmemektedir (Turan ve Uzun, 2018:228). Bu gelişmelerden istifade eden Yehova Şahitleri'nin gerek ülkemizde ve gerekse dünya çapında yaptı̆̆ı faaliyetlerde gösterdiği artışta teşkilatın yayınlarının payı çok büyüktür (Yasdıman, 2005: 116). Cumhuriyet kurulmadan önce de ülkemizde faaliyetlerini sürdüren Yehova Şahitleri, başlarda Amerika'da Türkçe basılmış kitap ve broşürleri dağıtarak faaliyette bulunuyordu. Daha sonraları Türkiye 'de de yazılı eserlerini de basma imkanını elde etmişler, 1974'te İstanbul'da "Mukaddes Kitap Kursları Derneği" adı altında kurulan dernek aracılığıyla çeşitli

Turkish Academic Research Review - Türk Akademik Araştırmalar Dergisi 
1282 Kaynak Mobilizasyon Kuramı Çerçevesinde Yehova Şahitlerinin Üye Kazanma Yöntemlerinin Tespiti ve Değerlendirilmesi (Antalya Örneği)

yayınlar çıkarmışlardır (Tümer, 1984: 498). Yine de buna rağmen hem "Gözcü" hem de "Uyanış" dergilerinin Türkçe baskıları genelde Almanya'da yapılmaktadır (Yasdıman, 2005: 120).

\section{İnternet}

Teknoloji dünyasında yaşanan gelişmeler toplumsal hayat şartlarında birtakım değişimleri de beraberinde getirerek bu yeni sosyal ilişki türlerinin ortaya çıkmasına sebep olmuştur. YDH'ler iletişim teknolojilerini takip etme ve kullanma hususunda gayet başarllıdırlar. Özellikle de iletişim teknolojilerinde yaşanan bu baş döndürücü gelişme, kitlelere ulaşma noktasında hem maliyet hem de zaman açısından en kolay ve hesaplı yol olarak karşımıza çıkmaktadır.

İletişim teknolojileri içerisinde internet en etkili ve verimli sosyal alanlardan birisi olarak karşımıza çıkmaktadır. Bireyler artık internet sayesinde her şeyden haberdar olabilmekte ve birbirleriyle kolayca iletişim kurabilmektedir. İnternet bireyleri özgürleştirmekle kalmayıp, onlara sınırsız sayıdaki seçenek arasından tercih yapabilme imkanı da sunabilmektedir (Karslı \& Aycan, 2020: 245-265).. Bu yönüyle internet hem geleneksel hem de yeni dini hareketler için bir rekabet ortamı sunmaktadır. Dolayısıyla YDH'ler sanal ortamın sunduğu "Pazar ekonomisinden" pay alabilmek ve üye sayısını arttırarak ayakta kalabilmek istiyorlarsa " Pazar araştırmaları" yapmak ve rakipleri hakkında her şeyi bilmek zorundadırlar (Ünal,2016:308). İnternet ortamı insanlara hem kendi dinleri hem de diğer dinler hakkında pek çok bilgiye rahatlıkla ulaşabilme imkanı vermiş̧ir. Bu durum YDH'ler için de geçerlidir. Özellikle sempatizan/üye kazanma hususunda cazip bir alan olan internet, YDH'lerin potansiyel üyelerine interaktif ortam aracıllı̆ı̆yla erişim imkanı sunmakta ve çeşitli dijital materyallere erişim noktasında büyük kolaylıklar sunmaktadır. Bu sayede dünyanın birçok yerinden çok sayıda insan YDH'ler ile bir şekilde iletişime geçebilmektedir. (Dawson \& Hennerbry,2004: 159-160;Turan ve Uzun, 2018:230-231).

Cowan (2007)'ın İnternet ve YDH'ler arasındaki ilişkiyi ele aldığı bir makalesinde internet üzerinden yürütülen dini aktivitelerin iki boyutta ele alındığı görülmektedir. Bunlar: "dinin çevrimiçi hali (religion online)" ve "çevrimiçi din (online religion)'dir. Dinin çevrimiçi boyutunda internet, dini grup ve cemaatler hakkında bilgi aktarımı sağlamakta, bu oluşumların kendi mevcut üyeleriyle irtibata geçmesinde aracılık etmektedir. Çevrim içi din boyutunda ise internet, üyelerin çeşitli platformlar üzerinden ibadetler, törenler, ritüeller vb. hakkında konuşmak, fikir paylaşımı yapmak amacıyla buluşup toplandığı bir yer olarak kullanılmaktadır. $\mathrm{Bu}$ noktada YDH'ler interneti kendilerini tanıtıp duyurma açısından dış dünyaya nazaran daha gerçekçi bir "ortam” olarak kabul etmektedir. 
İnternet üzerinden misyonerlik faaliyetlerinde bulunan yeni dini hareketlerden birisi de bu çalışmanın araştırma konusu olan Yehova Şahitleri'dir. Faaliyet yürüttükleri ülkenini dili dikkate alınarak hazırlanan sitede bu hareketin tarihçesi ve tanıtıcı bilgilerin yanında merak edilen sorulara Kutsal Kitap ışığında cevap verilmekte, bulundukları bölge ve şehrin iletişim bilgileri yer almaktadır. Ayrıca Yehova Şahitlerin resmi web sitesinde Türkçe de dahil 750’yi aşkın dilde çıkan eserleri mevcuttur. Teşkilatın yayınlarının çoğunun Türkçeye çevrilmiş baskısı da halıhazırda bulunmaktadır. $\mathrm{Bu}$ yayınlara sanal ortamdan da ulaşmak mümkümdür. Bunun için teşkilatın resmi web sitesi olan (https://www.jw.org/tr/) ziyaret edilebilir, sitenin online kütüphane bölümündeki türkçeye çevrilmiş yayınlar bilgisayar ve tabletlere de ücretsiz indirilebilir. Teşkilatın Türkçe yayınlanan ve internet ortamından ücretsiz indirilebilen bazı eserler şu şekildedir: Broşürler; Aile Hayatından Zevk Almak (2000), Barış Dolu Yeni Dünya (2000), Bu Dünya Varlı̆̆ını Sürdürecek Mi? (2000), Dünyayı Gerçekten Kim Yönetiyor? (2000), Gençler Yaşamınıza Nasıl Bir Yön Vereceksiniz? (2013), Gerçekleri Öğrenmek İster Misiniz? (2013), Kederli Olanlara Teselli (2000), Mukaddes Kitaba Güvenebilirsiniz (2000), Mukaddes Kitap Hakkında Bilgi (2002), Ölmüş Olan Iç̧in Ümit (2000), Tüm Acılar Bitecek (2005) vb. Kitapçıklar; Dinleyin Ve Yaşayın (2011), Doyum Veren Yaşam (2007), Hayat Nasıl Başladı? (2010), Iyi Haber (2012), Güzel Diyar ( 2003), Sevdiğiniz Biri Öldüğünde (2006), Türkiye'de Yehova Şahitleri (2001), Yaşamın Kökeni (2010) vb.” Kitaplar; Büyük Öğretmen (2003), Neler Öğrenebilirsiniz (2016), Ne Öğretiyor (2015), Örnek Alın (2013), Tanrının Krallı̆̆ Hüküm Sürüyor (2014), Tanrının Sevgisi (2016) vb. (https://wol.jw.org/tr/wol/library/r22/lptk/t $\% \mathrm{C} 3 \% \mathrm{BCm}-\mathrm{yay} \% \mathrm{C} 4 \% \mathrm{~B} 1 \mathrm{nlar}$ )

\section{Hastane Ziyaretleri}

Misyonerlik faaliyetleri konusunda sistemli bir çalışma yürüten Yehova Şahitleri, üye kazanma amacıyla hastane ziyaretlerinde de bulunmaktadır (Tümer, 1996: 79). Teşkilatın yayın organı olan Gözcü dergisindeki bir makalede 17 yaşındaki bir gencin hasta yatağında nasıl Yehova Şahidi olmaya karar verdiği kendi ifadeleriyle şu şekilde aktarılmaktadır: "Geçirdiğim motor kazası hakkında konuşmak istemiyordum. Tek söyleyebileceğim şu ki çok akılsızca ve dikkatsizce hareket ettim. Bir günde bütün yaşamım alt üst oldu ve hayat dolu bir gençken bir anda kendimi hastane odasında yatalak bir vaziyette buldum. $\mathrm{Bu}$ durumu kabullenmem çok zor oldu. Kendime sürekli “Yaşamamın artık ne anlamı var?” diye soruyordum. Yehova Şahidi arkadaşım olan José Maríe beni görmeye geldi ve bu bölgedeki diğer Yehova'nın Şahitleri'nin hastanede beni ziyaret etmesine vesile

Turkish Academic Research Review - Türk Akademik Araştırmalar Dergisi 
1284 Kaynak Mobilizasyon Kuramı Çerçevesinde Yehova Şahitlerinin Üye Kazanma Yöntemlerinin Tespiti ve Değerlendirilmesi (Antalya Örneği)

oldu. Şahitlerin düzenli olarak beni ziyaret etmesinden çok etkilendim. Yoğun bakımdan çıkar çıkmaz ilk işim Kutsal Kitabı incelemek oldu. İnsanların neden acı çektiğini ve öldüğ̈̈nü, ayrıca Yaratıı’nın neden kötü hadiselere izin verdiğini anladım. Tanrı'nın gelecekle ilgili vaatlerini de öğrendim: Gelecekte tüm dünya kusursuz insanlarla dolacak ve orada hiç kimse "hastayım" demeyecek (İşaya 33: 24). Hayatımda ilk defa heyecan verici bir ümide sahip oldum. Hastaneden ayrıldığımda Kutsal Kitabı incelemeye devam ettim ve hızlıca ilerledim. Hatta özel bir tekerlekli sandalye sayesinde Yehova Şahitleri'nin bazı ibadetlerini ve müjdeli haberini duyurma işine katıldım. 5 Kasım 1988'de 20 yaşındayken özel bir küvette suya batırılarak vaftiz edildim. Yehova, hayata bakış açımı tamamen değiştirmeme yardım etmişti” (Gözcü Kulesi, 2015: 9). Ülkemizde de diğer ülkelerle benzer şekillerde evlerde, caddelerde, sokaklarda, parklarda, pazarlarda faaliyet gösteren Yehova Şahitleri (Yasdıman, 2011: 83) için hastaneler de Tanrı Yehova'nın müjdeli haberini anlatmak için uygun mekanlar arasında görülmektedir. Özel Hastanelere giderek bekleme salonlarına Yehova'nın öğretilerini anlatan yayınları bırakmaları Yehova'nın adını her yerde ve her şartta duyurmaya çalıştıklarını göstermektedir (http://www.akasyam.com/samsunda-misyonerlik-faaliyeti-yapan-ozel-hastane147149/).

\section{Ekonomik Faaliyetler}

Güçlü misyoner faaliyetleriyle öne çıkan Yehova Şahitleri ekonomik yönden de çok önemli mali kaynaklara sahiptir. Hareketin en önemli gelir kaynaklarını, yapılan bağışlar oluşturmaktadır (Tümer, 1983: 497; Tanyu, 1984: 53). Teşkilatın diğer gelir kaynaklarının başında yayınladıkları kitap ve broşürlerinden gelen maddi gelirler bulunmaktadır. Teşkilatın sahip olduğu gösterişli bina ve ibadet salonları, yayınevleri, matbaalar, çiftlikler göz önüne alınırsa trilyonlara varan giderlerinin ve bir o kadar da gelirlerinin olduğu dikkat çekmektedir. Hareketin tüm gelirlerini ve gelir kaynaklarını tam olarak tespit etmek mümkün olmamakla beraber yapmış olduğu yatırımlara bakılarak devasa büyüklükteki bütçelerinden bahsedilebilir. Çünkü sadece birkaç büroya gönderdikleri çok küçük paralar bile hareketin ekonomik cephesi hakkında ipucu vermeye yetmektedir (Aydın, 2010: 268). 1990'lara kadar Şahitler tarla hizmeti sırasında dağıttıkları kitap ve broşürlerden bağış adı altında bir miktar ücret almaktaydı. Bu yayınları maddi durumu iyi olmayanların alabilmesi için bağış miktarı düşük tutuluyordu. Bağış yapacak durumda olmayanlardan ise herhangi bir ücret talep edilmiyordu.1990 yılında teşkilatın yönetim kurulunun aldığı karara göre dağıtılan yayınlar karşıllı̆ında hiçbir ücret talep edilmeyecek, bu konu hakkında hiçbir imada 
bulunulmayacaktı. Teşkilat gönüllü bağışta bulunmak isteyenler için düzenleme yapmış, tüm ibadet salonlarına teberru sandığ konulmuştur. Bunun yanında gönüllü olanlar teşkilatın resmi web sitesi olan jw.org. üzerinden elektronik yolla da bağış yapabildiği gibi ellerindeki gayrimenkulleri de hizmet amaçlı bağışlayabilmektedirler. Burada toplanan paralar dünya çapındaki faaliyetlerinin masrafları, ibadet salonlarının inşası ve bakımı, afet yardım çalışmaları ve yerel cemaatlerin harcamalarında kullanılmaktadır (God's Kingdom Rule, 2017:194-202).

\section{Eğitim Öğretim Faaliyetleri}

Şahitlerin yüksek kalitede eğitim almaları ve donanımlı misyoner yetiştirmek amacıyla kurdukları eğitim okulları bulunmaktadır. Burada yetişen şahitler başka ülkelerde misyonerlik hizmeti için görevlendirilmektedir. Bunlar; Gilead Okulu, Pionner Okulu ve fiziksel tesisleri olan Beytel'dir.

Pionner Okulu: Bu okulda "Yeni Dünya Çevirisi" adlı kutsal kitap ile ilgili eğitimin yanında başka dinler ve kültürler hakkında dersler de verilmektedir. $\mathrm{Bu}$ okuldan mezun olanlar dünyanın değişik ülkelerine özel görevle gönderilmektedirler. Toplam 126 şubesi olan "Ministerial Servant School" ise yetişkin ve yetişkin yardımcılarının yetiştirilmesi amacıyla açılmış okullardır. $\mathrm{Bu}$ okullardan mezun olanların bir kısmı Türkiye'de de faaliyette bulunmuştur (Yasdiman, 2011:120-121).

Gilead Okulu: İlk kez 1943 yılında açılmıştır. Teşkilatın en önemli misyoner yetiştiren okuludur. Temel görevi Hristiyanlığı ve merkezi yorumlarını Yehova Şahitleri öğretilerine göre yaymaktadır (Tanyu, 1984: 76). Bu okula girmek için en az 2 yıl öncü olmak, en az 3 yıl önce vaftiz olmak, 21-40 yaş arasında olmak, bekar veya en az 2 yıl evli olmak, çocuklara düşkün olmamak ve İngilizce bilmek mecburi tutulmaktadır (Tanyu, 1984: 114). Öğrencileri evli çiftlerden oluşan bu okulda Öncü Misyonerlik Okulu'nda verilen dersler daha ayrıntılı incelenir. Teşkilatın temel inanç esasları ile ilgili derslerin yanında tarih, dinler ve başka kültürler hakkında dersler de ilaveten verilir. Yehova şahitleri için bu okulun mezuniyet töreni önemli kutlamalardan biri kabul edilir. Bu okuldan mezun olan çiftler, Yehova Şahitleri'nin faaliyetlerinin az yürütüldüğü veya Yehova Şahitleri’nin hiç bulunmadığı ülkelere hizmet etmek için gönderilirler. İdari kadro, her çifte nereye tayin edildiğini tören esnasında anons eder ve gidecekleri yerler için tek yönlü biletler verilir. İkinci tayinlerine kadar görev bölgelerinde kalırlar. Bu zaman zarfında türlü ihtiyaçları organizasyon tarafından karşılanır. Bunların dışında cemaat ihtiyarlarını, gönüllü çalışanları ve öncüleri eğitmek için de zaman zaman

Turkish Academic Research Review - Türk Akademik Araştırmalar Dergisi 
1286 Kaynak Mobilizasyon Kuramı Çerçevesinde Yehova Şahitlerinin Üye Kazanma Yöntemlerinin Tespiti ve Değerlendirilmesi (Antalya Örneği)

özel kurslar açılmaktadır. New York'taki, Patterson Eğitim Merkezi'nde de özel eğitim verilmektedir (Yasdıman, 2011: 121-122).

Beytel: Gilead okulunda eğitim gören Yehova Şahitleri bu süre zarfinda kaldıkları binalardır. İbranice kökenli bir sözcük olan "Beytel” Türkçede "Tanrı evi" anlamına gelmektedir ${ }^{1}$. Yehova Şahitleri iyi haberi dünyanın dört bir yanına ulaştırmak amacıyla kullandıkları tüm binaları "Beytel" olarak adlandırmaktadır (Tagaev,2014:119).

\section{Vaaz Faaliyetleri}

Yehova Şahitlerinin daha fazla insana ulaşma ve üye kazanma propagandalarından birisi de vaaz etme faaliyetidir. Onlar, vaaz etme faaliyetinin İsa Mesih'in de tatbik ettiği bir uygulama olduğunu söylemektedirler ${ }^{2} \mathrm{Bu}$ inanışa göre İsa ve onun resulleri açıktan ve evden eve vaaz ederlerdi (Tanyu, 1984: 132). Yehova Şahitleri de insanların bulunabileceği her yere "krallığın iyi haberini" ulaştırmak için durmadan çalışırlar (Bearing Thorough Witness" About God's Kingdom, 2018: 7). Şahitler, etkiledikleri kişileri özellikle ev ortamlarında yapılan toplantılara davet ederek vaaz etmeye devam etmektedirler. Bu ev ortamı veya toplantı salonlarındaki samimi atmosfer muhataplar üzerinde derin izler bırakmakta ve şahitlerin arasındaki muhabbet ve sevgi bağlarını kuvvetlendirmektedir (Yasdıman, 2011: 122).

Yehova Şahitlerinin israrla ve inatla vaaz etmek faaliyetinde bulunmalarının altında yatan en önemli nedenin kendi aralarında kullandıkları "vaaz etmeyen Yehova Şahidi, Yehova Şahidi değildir." düsturu olduğu söylenebilir (Tanyu, 1984: 133). Bundan dolayı dünyanın dört bir tarafına dağılan şahitler, daha fazla vaaz ederek daha fazla insana ulaşmayı ve onları kurtarmayı kendilerine görev edinmişlerdir. (Yasdıman, 2011: 122). Hatta öyle ki Teşkilatın evli üyelerinden vaaz etmeye daha fazla zaman ayırabilmeleri için çocuk sahibi olmama yönünde telkinde bulunduğu de belirtilir (Paşaoğlu, 2016: 174).

\section{Toplantı Faaliyetleri}

Yehova Şahitleri'nin Türkiye'de yürüttüğü programlar Dünya çapında yürüttüğü programların bir uzantısıdır (Yasdıman, 2005: 213). Dolayısıyla Türkiye'deki toplantı faaliyetleri de dünyada diğer ülkelerde yaptığı toplantı faaliyetleri ile aynıdır. Türkiye'deki Şahitler, Yehova Şahitlerinin en büyük toplantısı olan uluslararası kongreye de katılmakta iseler de burada konumuzu asıl ilgilendiren toplantılar daha yerel olan toplantılardır. Bir ülkede, dolayısıyla

\footnotetext{
1 Yaratılış, 28:17-19.

2 Resullerin İşleri 20:20.
} 
Türkiye'de yapılan en büyük toplantı Bölge Kongresidir. Türkiye'de mazereti olanlar hariç bütün Yehova Şahitleri'nin bu kongreye katılmaları istenir. Bunun dışında Çevre Toplantısı denilen toplantılar da birkaç cemaatin katılmasıyla ve bölge kongresinden daha küçük bir grupla yapılan toplantılar olup, örneğin, İzmir' deki toplantılara Ayvalık, Kuşadası, Bodrum, Marmaris, Akçay, Antalya, Eskişehir gibi yerlerdeki cemaat üyeleri iştirak eder. Yerel guruplar, kaç cemaat varsa, birleşerek bu toplantılara giderler (Yasdıman, 2011: 220-221). Antalya, Yehova Şahitleri misyonerlik faaliyetlerini yoğun olarak sürdürdüğü illerden biridir. Antalya'da Yehova şahitleri genellikle merkeze bağlı Konyaaltı, Kepez ve Muratpaşa ilçelerinde ikamet etmektedir. Şehrin merkezinde bulunan Muratpaşa ilçesinde ibadet salonları mevcuttur. Şahitler bu salonlarda hafta içinde toplanırlar. Katılan gurupların dillerine göre toplantılar farklı günlerde organize edilir. Örneğin İngilizce bilenler belli bir günde, Rusça bilenler belli günlerde toplanır. Eğer ibadet salonuna gelen şahitlerin sayısı tahmin edilenden fazla olursa bu sefer toplantıların daha verimli geçmesi için gruplar bölünür ve her grup farklı saat ve günlerde bir araya gelir. Genel olarak bu toplantılara devam etmek önemlidir. Yehova Şahidi erkekler birbirine "birader" kadınlar ise "hemşire" şeklinde hitap etmektedirler. Bu araştırma çerçevesinde Muratpaşa ilçesinde yer alan toplantı salonunun gösterişten uzak ve sade olduğu gözlemlenmiştir. Hiçbir dini sembolün olmadığı, toplantı salonunda sadece konuşma yapacak kişi için kürsü ve şahitler için sandalyeler mevcut olduğu tespit edilmiştir. Salonlarda "teberru sandığı" yani bağış sandığı bulunmakta, bağışta bulunmak konusu da gönüllülük esasına dayanmaktadır.

Örneklem alanında yapılan görüşmelerde "ibadet merkezlerine neden "kilise" demedikleri sorulduğunda" Kutsal Kitap'ta "kilise" olarak çevrilen sözcügüule ibadet mekanı değil de, oraya toplanan cemaatin kastedildiği söylenmiştir. Dolasıyla Yehova Şahitleri olarak ibadet yerlerini ibadet salonu olarak adlandırdıkları ifade edilmiş, şahitler olarak bu mekanlarda ibadet etmek ve O'nun hakkında şahitlik etmek için bir araya geldikleri belirtilmiştir. "Dışarıdan her isteyen bu toplantılara girebilir mi?" diye sorulduğunda ibadetlerin Yehova'nın Şahidi olsun olmasın herkese açık olduğu ifade edilmiştir. Toplantıya katılan Şahitlerin bir kısmının yanlarında İncil ve aylık dergileriyle geldikleri, diğerlerinin de telefon ve tabletlerle toplantıyı takip etmeyi tercih ettikleri gözlenmiştir. Görüşülen şahısların aktardıklarına göre artık haftalık ve aylık programların interaktif ortamdan takip edildiği, Şahitlerin çoğunun da teknolojinin imkanlarından istifade ettikleri anlaşılmaktadır. Şahitlerin haftalık yapılacak toplantıları artık teşkilatın resmi dijital uygulaması olan JW Library üzerinden takip ettikleri, Şahitlerin çoğunun da cep telefonunda bu uygulamayı indirdiği belirtilmiştir. Farklı dil seçeneğinin sahip bu

Turkish Academic Research Review - Türk Akademik Araştırmalar Dergisi https://dergipark.org.tr/tr/pub/tarr 
uygulamanın içerisinde Yehova Şahitleri hakkında her türlü bilginin bulunduğu, şahitlerin haftalık yapılacak toplantılarda işlenecek konular hakkında bilgi edindikleri ifade edilmiştir. Ayrıca bu uygulamada birçok Kutsal Kitap çevirisinin yanı sıra Kutsal Kitabı incelemeye yardımcı kitap ve kitapçıklar da bulunduğunun, Yehova Şahitlerinin faaliyetlerinin anlatan online kütüphane bölümünün olduğunun, dijital ortamda bağı̧̧ yapılabildiğinin, bu uygulamayı yapan kişilerin bilgisayar programcılığ toplantılarda "her gurubun farklı konuları mı ele aldığı" sorulduğunda, dünyanın neresine giderseniz gidin ibadet salonlarında aynı programın ele alındığı söylenmiştir. Hafta içi yapılan toplantılarda konuşmacıların sürekli değiştiği gözlemlenmiştir. Bunun sebebi sorulduğunda toplantının verimli geçmesi ve Şahitlerin motivasyonlarını diri tutmak amaciyla böyle bir uygulamayı tercih ettikleri belirtilmiştir. Ayrıca Şahitlere güzel konuşma sanatıyla ilgili derslerin de verildiği tespit edilmiştir. Programlar genellikle bir duayla başlanmakta, ilahi ve ortamın anlam ve önemine uygun şekilde İncil'den bazı bölümler seçilerek söz konusu pasajlar hakkında açıklamada bulunulmaktadır. Kapanış da yine duayla yapılmakta, dua esnasında ayağa kalkılıp bitişinde "amin" denilmektedir. Hafta sonu yapılan ibadetler ise yaklaşık bir saat sürmektedir. İlk yarım saatte genellikle kutsal kitaba dayanan ve ortalama 30 dakika süren halka yönelik bir konuşma yapılır. Diğer yarım saatte ise Gözcü dergisindeki bir makale soru-cevap şeklinde incelenir ve isteyen herkes cevap verebilir. Dergiler, Şahitlerin evlerine aylık gönderilir. Teknolojinin gelişmesiyle birlikte Şahitler, söz konusu makaleleri resmi web uygulaması olan Jw Library üzerinden takip edip toplantıya gelmeden önce de o hafta okuyacakları makaleyi çalışırlar.

\section{Sonuç}

Dünya genelinde yeni dini hareketlerin çeşitlilik arz etmesi bu hareketlerin nasıl ve ne şekilde taraftar topladığı konusunda genel geçer bir modelin ortaya konmasını zorlaştırmaktadır. Sosyolojik olarak bilinen bir gerçek vardır ki herhangi toplumsal hareketin varlı̆̆ını devam ettirebilmesi için belli kaynaklara ihtiyacı vardır. Özellikle enformasyon çağı olarak adlandırılan günümüz dünyasında herkes herşeyden haberdar olmaktadır. Bu durum yeni dini hareketler için rekabet ortamı yaratmış, öğretilerini daha fazla insana ulaştırmak ve üye kazanmak için zaman ve ekonomi açısından en uygun yöntemlere başvurma yoluna gitmişlerdir. $\mathrm{Bu}$ çalışmada yapılan literatür çalışmasının yanında, yapılan mülakat ve gözlemler neticesinde Yehova Şahitlerinin tebliğ faaliyetlerini ve üye kazanma stratejilerini açıklamak üzere kaynak mobilizasyon kuramı kullanılmıştır. Bu çerçevede teşkilatın 
kendi öğretilerindeki müjdeli haberi tüm insanlığa ulaştırma ve sahip olduğu potansiyel kaynakları harekete geçirmek adına izlediği stratejileri şu şekilde sıralamak mümkündür:

$>$ Şahitlerin, Tanrı'nın müjdeli haberini diğer insanlara ulaştırmak için ev, hastane ziyareti gibi tüm iletişim kanallarını etkili bir şekilde kullandığı görülmektedir.

$>$ Teşkilat, üyelerini/müjdecilerini sahada (tarla hizmetinde) etkin bir şekilde yönlendirebilmektedir. $\mathrm{Bu}$ bağlamda üyelerinden tebliğ faaliyetleri sırasında güler yüzlü olmasını ve giyim-kuşamına önem vermesini istemektedir.

> Teşkilat, tebliğ faaliyetlerinde kullanılan kitap, broşür gibi yayınların basımında kaliteye ve eserlerde kullanılan resim ve fotoğrafların seçimine önem vermektedir. Bu da insanların dikkatini çekmektedir

$>$ Yehova Şahitlerinin faaliyetleri esnasında bulundukları çevrenin sosyokültürel ortamını dikkate aldıkları ve muhataplarıyla iletişim kurarken inanç bağlamındaki tartışmalı konulardan kaçındıkları bilinmektedir.

> İletişim teknolojilerinin gelişmesiyle küresel bir köye dönen dünyamızda sanal ortam Yeni dini hareketler için cazip bir platform haline gelmiştir. Yehova Şahitleri de bu değişime ayak uydurmuş, sanal ortamda da faaliyetlerini etkin bir şekilde sürdürmeyi başarmıştır.

> Teşkilat, üyelerinin tebliğ konusunda donanımlı olması için sistematik olarak çalışmaktadır. İnsanları ikna etme hususunda müjdecilere teknik eğitim verilmektedir. Üyelerine teolojik bilgilerin yanında, vaaz hizmetleri için güzel konuşma sanatı dersleri de verilmektedir.

$>$ Yehova Şahitleri dünya çapında faaliyet gösteren bir hareket olduğu için faaliyetlerinde kar-zarar amacı gütmemektedir. Teşkilat bu noktada şahitliği yeni kabul etmiş birisinden zorla bağış veya aidat almamakta, gönüllülüğü esas tutmaktadır.

\section{Kaynakça}

Aydın, M. (2010). Türkiye'ye Yönelik Batı Kökenli Dini Cereyanlar. Konya: Nüve Kültür Merkezi Yayınları.

Bird, F.B. and Westley,F.(1985). "The Economic Stragegies of New Religious Movement”, Sociological Analysis 46(2):157-170.

Bilgin, V. (2020). "Din ve Toplumsal Sorunlar". Din Sosyolojisi. K. Canatan ve M. Tekin (Ed.). Ankara: Bilimsel Araştırma Yayınları. 
1290 Kaynak Mobilizasyon Kuramı Çerçevesinde Yehova Şahitlerinin Üye Kazanma Yöntemlerinin Tespiti ve Değerlendirilmesi (Antalya Örneği)

Bodur, H. E. (2003). "Moonculuk Hareketi ve Türkiye'de Benzer Bir Yapılanmanın Sosyolojik Analizi". Kahramanmaraş Sütçü İmam Üniversitesi Ilahiyat Fakültesi Dergisi, 1(1) : 13-39.

Cowan, D.E. (2007). "Teaching New Religious Movements on the World Wide Web”. D. G. Bromley ( Ed.) Teaching New Religious Movements, Oxford University Press, New York, 291-308.

Dawson, L. L. (2003). Cults and New Religious Movements, Blackwell Publishing, Oxford.

Dawson, L. L. \& Hennebry, J. (2004). "New Religions and The Internet". L. L. Dawson \& D. E. Cowan (Eds). Religion Online Finding Faith on the Internet, Routledge, New York,159-160.

Karsl1, B. \& Aycan, S. (2020). "Instagram ve Mahremiyet: Dindar Muhafazakâr Kadınların Paylaşımları Örneği”. Turkish Academic Research Review, 5(2). 245-265.

Kirman, M. A. (2004).’'Küresel Kült Savaşlarının Yapıldı̆̆g Meydan:Gençlik ve Aile”, Diyanet İlmi Dergi, 40(2):61:72.

Kirman, M. A. (2010). Yeni Dini Hareketler Sosyolojisi, Ankara: Bileşik Yayınları.

McCarthy, J. D. \& Zald, M. N. (1977). "Resource Mobilization and Social Movements: A Partial Theory", American Journal of Sociology, 82(6), 1212-1241.

Paşaoğlu, S. (2016). Tarih ve Öğretileriyle Yehova Şahitleri, İstanbul: GDK yayınlar1.

Schaefer, R. T. (2013). Sosyoloji. (Çev. S. Coşar). İstanbul: Palme Yayıncilik.

Stark, R. L. (2003). "Why Religious Movements Succeed or Fail: A Revised General Model", Cults and New Religious Movements: A Reader, (Ed.). L. L. Dawson, Blackwell Publishing, Oxford, 259-270.

Tanyu, H. (1980). Yehova Şahitleri, Ankara: DİB Yayınları.

Tinaz, N. "Yehova Şahitleri”. TDV İslam Ansiklopedisi, C.XXXXIII, s. 391396.

Turan, S. ve Uzun, S.N.(2018)."Yeni Dini Hareketlerin Taraftar Kazanma Yöntemleri”. S. Turan ve F. Sancar (Ed.). Nedenler ve Niçinleriyle Yeni Dini 
Hareketler, İstanbul: Metamorfoz Yayıncılık. s. 212-241.

Tümer, G.(1983).”Yehova Şahitlerinin Mahiyeti veÜlkemizdeki Mer'i Hukuk Karşısındaki Durumu” " Illahiyat Fakültesi Dergisi,26:491-548

Tümer, G. (1996a). "Yehova Şahitlerinin İnanç Sistemi Nasıldır?", Türkiye'de Misyonerlik Faaliyetleri, ss.79-83.

Tümer.G. (1996b). "XIX. Yüzyılda Sömürgecilerin Destek Kuvveti Misyonerlik ve Yehova Şahitleri Gerçeği”, Türkiye'de Misyonerlik Faaliyetleri, ss.53-63.

Yehova Şahitleri (2001). Türkiye'de Yehova'nın Şahitleri, İstanbul: Kule Kitapları.

Uysal, A. (2009). Toplumsal Hareketler İçin Kaynak Yaratma ve Kullanma Stratejileri. Eskişehir Osmangazi Üniversitesi Sosyal Bilimler Dergisi, 10(2), 217 238.

Ünal, M. S.(2016).”Yeni Dini Hareketler ve İnternet ." S. Turan ve F. Sancar (Ed.). Nedenler ve Niçinleriyle Yeni Dini Hareketler Metamorfoz Yayıncıllk, İstanbul, 307-321.

Watch Tower Bible and Tract Society of Pennsylvania .(2015). Gözcü Kulesi (1 Ocak 2014). Watchtower Bible and Tract Society of Britain, Germany.

Watch Tower Bible and Tract Society of Pennsylvania .(2015).Gözcü Kulesi (1 Ağustos 2015). Watchtower Bible and Tract Society of Britain, Germany.

Watch Tower Bible and Tract Society of Pennsylvania .(2017).God's Kingdom's Rule. Druck und Verlag: Wachtturm Bibelund Traktat-Gesellschaft, Selters/Ts., Germany.

Watch Tower Bible and Tract Society of Pennsylvania Watch Tower Bible and Tract Society of Pennsylvania .(2018).Bearing Thorough Witness" About God's Kingdom Watchtower Bible and Tract Society of Britain, Germany.

Yasdıman, H. (2005). "Yehova Şahitlerinin Teşkilat Yapısı ve Türkiye'deki Faaliyetleri(1)” Dokuz Eylül Fakültesi Illahiyat Fakültesi Dergisi, 21:193-221.

Yasdıman, H. (2011). Yehova Şahitleri Tarihçe, Teşkilat Inanç İbadet ve Uygulamalar. İzmir: Tibvan Yayıncılık.

"Yehova Şahitleri'nin Türkiye'deki Sayısı"

https://www.jw.org/tr/yehovanin-sahitleri/dunya-capinda/TR/ (erişim tarihi:19/04/2020).

Turkish Academic Research Review - Türk Akademik Araştırmalar Dergisi https://dergipark.org.tr/tr/pub/tarr 
1292 Kaynak Mobilizasyon Kuramı Çerçevesinde Yehova Şahitlerinin Üye Kazanma Yöntemlerinin Tespiti ve Değerlendirilmesi (Antalya Örneği)

"Yehova Şahitleri'nin Resmi İnternet Sitesi" https://www.jw.org/tr// (erişim tarihi:19/04/2020).

"Yehova Şahitleri’nin Yayınları" https://wol.jw.org/tr/wol/library/r22/lptk/t\%C3\%BCm-yay $\% C 4 \% B 1$ nlar (erişim tarihi: $16 / 04 / 2020$ ).

“Samsun'da Misyonerlik Yapan Özel Hastane".

http://www.akasyam.com/samsunda-misyonerlik-faaliyeti-yapan-ozel-hastane-

147149/ (erişim tarihi: 15/04/2020). 